\title{
29. ELECTRON MICROPROBE AND THERMOMAGNETIC ANALYSIS OF BASALT SAMPLES FROM HOLE 597C 1
}

\author{
Tadashi Nishitani, Institute of Mining Geology, Mining College, Akita University, Akita, Japan²
}

\begin{abstract}
Electron microprobe and thermomagnetic analyses of selected basalt samples from Hole 597C were performed. The main purpose of this work was to investigate and estimate the degree of oxidation of the samples using the ratios of $\mathrm{Fe}$ to $\mathrm{Ti}$ and the Curie temperatures obtained from thermomagnetic curves. The results show that the magnetic properties of samples from Hole $597 \mathrm{C}$ change at a sub-bottom depth of $100 \mathrm{~m}$, and that low-temperature and high-temperature oxidation processes prevailed above and below $100 \mathrm{~m}$, respectively.
\end{abstract}

\section{INTRODUCTION}

The degree of oxidation of a rock holds a key to the thermal history of the rock. Weathering processes and thermal effects can change the magnetic properties of a rock. Thermomagnetic analysis, which indicates the change in saturation magnetization as a function of temperature, can also directly indicate the degree of alteration. A rock sample which was never altered shows almost the same thermomagnetic curves during heating and cooling. The Curie temperature (or Curie point) is determined from the thermomagnetic curve as the intersection of tangents drawn above and below the smooth extensions at each side of the curve's inflection.

Two oxidation processes are involved in the oxidation of titanomagnetites: high- and low-temperature oxidation.

High-temperature oxidation is a decomposition process and produces observable lamellae, titanium-rich rhombohedral phases, and iron-rich spinel (Buddington and Lindsley, 1964; Hauptman, 1974). The spinel is dominant in the rock's magnetic properties and shows a $\mathrm{Cu}$ rie temperature of more than $500^{\circ} \mathrm{C}$ in the heating process of thermomagnetic analysis. The thermomagnetic cooling curve is almost the same as the heating curve.

Low-temperature oxidation of titanomagnetites is a process of converting from the stoichiometric state to the cation-deficient state. For low-temperature oxidation, the degree of oxidation is represented by the oxidation parameter $z$ defined as the fraction of original $\mathrm{Fe}^{2+}$ converted to $\mathrm{Fe}^{3+}$ :

$$
\begin{aligned}
\mathrm{Fe}^{2+}+\frac{z}{2} \mathrm{O} \rightarrow z \mathrm{Fe}^{3+}+ & (1-z) \mathrm{Fe}^{2+}+\frac{z}{2} \mathrm{O}^{2-} \\
& (0 \leq z \leq 1) .
\end{aligned}
$$

$z=0.0$ indicates stoichiometric titanomagnetite and $z=$ 1.0 indicates the fully oxidized state (Ozima and Sakamoto, 1971). The Curie temperature generally increases

\footnotetext{
${ }^{1}$ Leinen, M., Rea, D. K., et al., Init. Repts. DSDP, 92: Washington (U.S. Govt. Printing Office). pan.
}

as the degree of low-temperature oxidation increases; that is, as $z$ increases (Nishitani and Kono, 1983). The cation-deficient phase is unstable when heated above 400 to $450^{\circ} \mathrm{C}$, and consequently it decomposes to an ironrich stoichiometric titanomagnetite (spinel phase) and a hemo-ilmenite (rhombohedral phase) during the thermomagnetic heating process. Saturation magnetization $\left(J_{s}\right)$ increases with the addition of iron-rich titanomagnetite, but $J_{s}$ decreases as the temperature approaches the $\mathrm{Cu}$ rie point. Therefore, a peak can be observed in the heating curve. The saturation magnetization during cooling shows a sharp rise owing to the new phase. In summary, typical low-temperature oxidation products show the characteristic feature of thermomagnetic curves, a peak during heating and a sharp rise during cooling (Ozima and Ozima, 1971). Some samples show lower Curie temperatures in a cooling cycle than in a heating cycle, depending on the sample size (Hamano et al., 1980).

We investigated the state of oxidation of 24 basalt samples from Hole 597C using electron microprobe and thermomagnetic methods. As already mentioned, we are able to interpret from thermomagnetic analysis whether a rock sample has been affected by a high- or low-temperature oxidation process or by no oxidation process at all. Using the ratios of $\mathrm{Fe}$ to $\mathrm{Ti}$ and titanomagnetite compositions determined by electron microprobe analyses, we can also obtain information on the degree of oxidation at low temperatures from the Curie temperature observed in a heating cycle (Nishitani and Kono, 1983).

\section{RESULTS OF ELECTRON MICROPROBE ANALYSES}

Two hundred and four points were analyzed from 24 samples using an electron microprobe analyzer (JXA-5). Analyzed components were $\mathrm{FeO}, \mathrm{TiO}_{2}, \mathrm{Al}_{2} \mathrm{O}_{3}, \mathrm{MgO}$, $\mathrm{MnO}, \mathrm{CaO}, \mathrm{SiO}_{2}$, and $\mathrm{K}_{2} \mathrm{O}$. Qualitative analysis showed no trace of $\mathrm{Na}$ (sodium) and V (vanadium). Some samples were analyzed quantitatively for As (arsenic) and S (sulfur); their quantities were not detected, however, except as pyrrhotite. Correction factors were calculated according to the method of Bence and Albee (1968).

Results are summarized in Table 1 . The mean values of each component are shown in Table 2; parentheses in- 
Table 1. Results of electron microprobe analysis, Hole 597C samples.

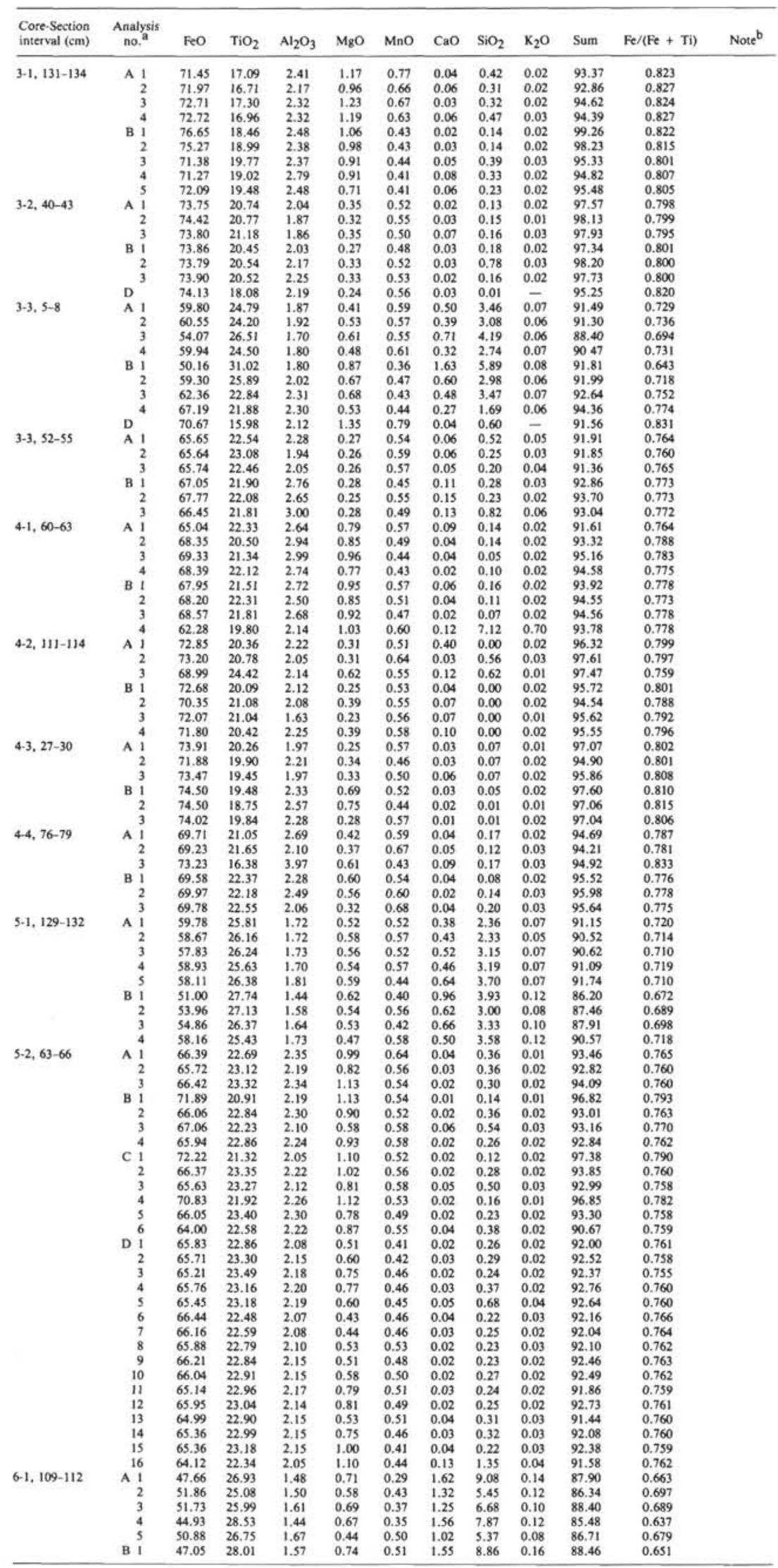


Table 1 (continued).

\begin{tabular}{|c|c|}
\hline $\begin{array}{l}\text { Core-Section } \\
\text { interval }(\mathrm{cm})\end{array}$ & $\begin{array}{l}\text { Analysis } \\
\text { no. }{ }^{2}\end{array}$ \\
\hline $6-1,109-112$ & B 2 \\
\hline & 3 \\
\hline $6-5,58-61$ & A 1 \\
\hline & 2 \\
\hline & 3 \\
\hline & B 1 \\
\hline & 2 \\
\hline & 3 \\
\hline $7-1,115-118$ & A 1 \\
\hline & 2 \\
\hline & 3 \\
\hline & 4 \\
\hline & B 1 \\
\hline & 2 \\
\hline & 3 \\
\hline & 4 \\
\hline $7-2,16-18$ & A 1 \\
\hline & 2 \\
\hline & 3 \\
\hline & 4 \\
\hline & 5 \\
\hline & B 1 \\
\hline & 2 \\
\hline & 3 \\
\hline & 4 \\
\hline & 5 \\
\hline $7-4,18-21$ & A 1 \\
\hline & 2 \\
\hline & B 1 \\
\hline & 2 \\
\hline $8-3,130-133$ & A 1 \\
\hline & 2 \\
\hline & 3 \\
\hline & 4 \\
\hline & B I \\
\hline & 2 \\
\hline $8-4,102-105$ & A 1 \\
\hline & 2 \\
\hline & B 1 \\
\hline & C i \\
\hline & 2 \\
\hline & 3 \\
\hline $8-7,9-12$ & A 1 \\
\hline & 2 \\
\hline & 3 \\
\hline & B 1 \\
\hline & $\mathrm{C}_{1}$ \\
\hline & 2 \\
\hline & 3 \\
\hline & 4 \\
\hline $9-3,88-91$ & A 1 \\
\hline & 2 \\
\hline & 3 \\
\hline & 4 \\
\hline & B 1 \\
\hline & 2 \\
\hline & 3 \\
\hline & 4 \\
\hline $9-4,103-106$ & A 1 \\
\hline & 2 \\
\hline & 3 \\
\hline & 4 \\
\hline & B 1 \\
\hline & 2 \\
\hline & 3 \\
\hline $10-1,112-115$ & A 1 \\
\hline & 2 \\
\hline & 3 \\
\hline & 4 \\
\hline & B 1 \\
\hline & 2 \\
\hline & 3 \\
\hline & 4 \\
\hline $10-5,84-87$ & A 1 \\
\hline & 2 \\
\hline & 3 \\
\hline & B 1 \\
\hline & 2 \\
\hline & 3 \\
\hline & c \\
\hline & D \\
\hline $10-7,42-45$ & A 1 \\
\hline & 2 \\
\hline & 3 \\
\hline & 4 \\
\hline & B I \\
\hline & 2 \\
\hline & 3 \\
\hline $11-4,62-64$ & A 1 \\
\hline & 2 \\
\hline & 3 \\
\hline & 4 \\
\hline & B I \\
\hline & 2 \\
\hline & 3 \\
\hline & c \\
\hline
\end{tabular}

Note: All data except $\mathrm{Fe} /(\mathrm{Fe}+\mathrm{Ti})$ are expressed in wt, $\%$

b On lam. means that the position of an analysis point is on a lamella. Betw. lam. means that the position of an analysis point is between

lamellac. Fes means pyrrhotite. 
Table 2. Mean value of each component, Hole $597 \mathrm{C}$ samples.

\begin{tabular}{|c|c|c|c|c|c|c|c|c|c|}
\hline $\begin{array}{l}\text { Core-Section, } \\
\text { interval }(\mathrm{cm})^{\mathrm{a}}\end{array}$ & $\mathrm{FeO}$ & $\mathrm{TiO}_{2}$ & $\mathrm{Al}_{2} \mathrm{O}_{3}$ & $\mathrm{MgO}$ & $\mathrm{MnO}$ & $\mathrm{CaO}$ & $\mathrm{SiO}_{2}$ & $\mathrm{~K}_{2} \mathrm{O}$ & Sum \\
\hline $3-1,131-134$ & $72.83(1.88)$ & $18.20(1.19)$ & $2.41(0.17)$ & $1.01(0.17)$ & $0.54(0.14)$ & $0.05(0.02)$ & $0.31(0.12)$ & $0.02(0.00)$ & $95.37(2.11)$ \\
\hline $3-2,40-43$ & $73.92(0.25)$ & $20.70(0.27)$ & $2.04(0.16)$ & $0.33(0.03)$ & $0.52(0.02)$ & $0.03(0.02)$ & $0.26(0.26)$ & $0.02(0.01)$ & $97.82(0.33)$ \\
\hline $3-3,5-8$ & $59.17(5.14)$ & $25.20(2.79)$ & $1.97(0.23)$ & $0.60(0.14)$ & $0.50(0.09)$ & $0.61(0.44)$ & $3.44(1.22)$ & $0.07(0.01)$ & $91.56(1.71)$ \\
\hline $3-3,52-55$ & $66.38(0.88)$ & $22.31(0.48)$ & $2.45(0.42)$ & $0.27(0.01)$ & $0.53(0.05)$ & $0.09(0.04)$ & $0.38(0.24)$ & $0.04(0.01)$ & $92.45(0.89)$ \\
\hline $4-1,60-63$ & $67.26(2.38)$ & $21.47(0.90)$ & $2.67(0.27)$ & $0.89(0.09)$ & $0.51(0.06)$ & $0.05(0.04)$ & $0.99(2.48)$ & $0.11(0.24)$ & $93.94(1.10)$ \\
\hline $4-2,111-114$ & $71.71(1.52)$ & $21.17(1.48)$ & $2.07(0.21)$ & $0.36(0.13)$ & $0.56(0.04)$ & $0.12(0.13)$ & $0.17(0.29)$ & $0.02(0.01)$ & $96.12(1.10)$ \\
\hline $4-3,27-30$ & $73.71(0.98)$ & $19.61(0.52)$ & $2.22(0.23)$ & $0.44(0.22)$ & $0.51(0.05)$ & $0.03(0.02)$ & $0.05(0.03)$ & $0.02(0.01)$ & $96.59(1.01)$ \\
\hline $4-4,76-79$ & $70.25(1.48)$ & $21.03(2.34)$ & $2.60(0.71)$ & $0.48(0.13)$ & $0.59(0.09)$ & $0.05(0.02)$ & $0.15(0.04)$ & $0.03(0.01)$ & $95.16(0.67)$ \\
\hline $5-1,129-132$ & $56.81(2.89)$ & $26.32(0.73)$ & $1.67(0.11)$ & $0.55(0.04)$ & $0.51(0.07)$ & $0.57(0.17)$ & $3.17(0.55)$ & $0.08(0.02)$ & 89.70 (1.97) \\
\hline $5-2,63-66$ & 66.35 (1.95) & $22.79(0.59)$ & $2.17(0.08)$ & $0.79(0.22)$ & $0.50(0.06)$ & $0.03(0.02)$ & $0.34(0.23)$ & $0.02(0.01)$ & $93.00(1.56)$ \\
\hline $6-1,109-112$ & $50.25(3.43)$ & $26.59(1.25)$ & $1.56(0.08)$ & $0.63(0.10)$ & $0.43(0.08)$ & $1.27(0.30)$ & 6.90 (1.62) & $0.12(0.03)$ & $87.74(1.45)$ \\
\hline $6-5,58-61$ & $68.45(1.34)$ & $21.86(0.32)$ & $2.17(0.08)$ & $0.49(0.13)$ & $0.59(0.04)$ & $0.06(0.01)$ & $0.39(0.26)$ & $0.04(0.02)$ & $94.03(1.12)$ \\
\hline $7-1,115-118$ & $73.63(0.31)$ & $20.68(0.45)$ & $1.89(0.12)$ & $0.28(0.08)$ & $0.54(0.03)$ & $0.05(0.02)$ & $0.22(0.02)$ & $0.03(0.01)$ & $97.32(0.20)$ \\
\hline $7-2,16-18$ & $72.04(0.89)$ & $20.96(0.63)$ & $1.80(0.20)$ & $0.28(0.07)$ & $0.40(0.03)$ & $0.05(0.04)$ & $0.19(0.07)$ & $0.00(0.00)$ & $95.78(0.46)$ \\
\hline $7-4,18-21$ & $72.03(1.08)$ & $21.06(0.88)$ & $1.81(0.11)$ & $0.38(0.03)$ & $0.55(0.02)$ & $0.07(0.03)$ & $0.30(0.03)$ & $0.02(0.01)$ & $96.23(0.43)$ \\
\hline $8-3,130-133(0)$ & $55.46(9.05)$ & 42.17 (11.05) & $0.42(0.48)$ & $0.32(0.13)$ & $0.57(0.11)$ & $0.00(0.00)$ & $0.18(0.04)$ & $0.01(0.00)$ & $99.14(1.70)$ \\
\hline (b) & $79.10(0.67)$ & $13.72(0.11)$ & $1.92(0.23)$ & $0.16(0.01)$ & $0.36(0.03)$ & $0.02(0.01)$ & $0.17(0.01)$ & $0.02(0.01)$ & $95.45(0.30)$ \\
\hline $8-4,102-105(0)$ & 58.73 (3.32) & $36.23(6.22)$ & $0.54(0.32)$ & $0.41(0.01)$ & $0.67(0.06)$ & $0.05(0.03)$ & $0.76(0.88)$ & $0.03(0.01)$ & $97.41(1.59)$ \\
\hline (b) & $78.17(2.83)$ & $15.84(0.94)$ & $1.65(0.51)$ & $0.19(0.08)$ & $0.38(0.09)$ & $0.02(0.03)$ & $0.17(0.06)$ & $0.02(0.01)$ & $96.45(1.14)$ \\
\hline $8-7,9-12(0)$ & $49.38(1.23)$ & $49.82(0.38)$ & $0.07(0.04)$ & $0.77(0.18)$ & $0.65(0.04)$ & $0.01(0.01)$ & $0.14(0.02)$ & $0.02(0.01)$ & $100.89(1.09)$ \\
\hline (b) & $77.93(1.07)$ & $15.72(0.81)$ & $0.22(0.16)$ & $0.25(0.04)$ & $0.42(0.02)$ & $0.02(0.01)$ & $0.16(0.03)$ & $0.02(0.01)$ & $96.53(0.65)$ \\
\hline $9-3,88-91(0)$ & $55.26(5.01)$ & $39.95(7.87)$ & $0.73(0.52)$ & $0.81(0.06)$ & $1.72(0.26)$ & $0.02(0.01)$ & $0.19(0.02)$ & $0.02(0.00)$ & $98.69(2.16)$ \\
\hline (b) & $78.86(2.08)$ & $13.05(2.76)$ & $1.56(0.60)$ & $0.33(0.07)$ & $0.42(0.06)$ & $0.02(0.02)$ & $0.16(0.02)$ & $0.03(0.01)$ & $94.42(0.97)$ \\
\hline $9-4,103-106(0)$ & $56.05(5.63)$ & $42.66(6.39)$ & $0.60(0.45)$ & $0.82(0.10)$ & $0.63(0.07)$ & $0.01(0.01)$ & $0.16(0.01)$ & $0.02(0.00)$ & $100.96(0.41)$ \\
\hline (b) & $80.35(1.12)$ & $13.18(0.81)$ & $1.82(0.60)$ & $0.36(0.10)$ & $0.37(0.02)$ & $0.03(0.01)$ & $0.20(0.14)$ & $0.02(0.01)$ & $96.31(0.86)$ \\
\hline $10-1,112-115(0)$ & $47.99(0.25)$ & $49.63(0.51)$ & $0.03(0.02)$ & $0.66(0.11)$ & $0.64(0.01)$ & $0.02(0.02)$ & $0.04(0.06)$ & $0.02(0.01)$ & $99.02(0.82)$ \\
\hline & $76.04(0.93)$ & $16.87(0.64)$ & $0.97(0.20)$ & $0.28(0.01)$ & $0.45(0.02)$ & $0.03(0.03)$ & $0.09(0.05)$ & $0.02(0.01)$ & $94.75(0.58)$ \\
\hline $10-5,84-87$ & $73.13(0.78)$ & $20.65(0.31)$ & $1.23(0.19)$ & $0.58(0.11)$ & $0.53(0.10)$ & $0.02(0.01)$ & $0.12(0.04)$ & $0.02(0.01)$ & $96.26(0.52)$ \\
\hline $10-7,42-45$ & $71.72(0.57)$ & $21.84(0.55)$ & $1.36(0.10)$ & $0.72(0.14)$ & $0.52(0.09)$ & $0.01(0.02)$ & $0.09(0.02)$ & $0.02(0.00)$ & $96.28(0.51)$ \\
\hline $11-4,62-64$ & & & & & & & & & $97.71(0.78)$ \\
\hline (b) & $76.90(0.00)$ & $15.90(0.00)$ & $2.62(0.00)$ & $1.15(0.00)$ & $0.35(0.00)$ & $0.02(0.00)$ & $0.10(0.00)$ & $0.02(0.00)$ & $97.08(0.00)$ \\
\hline
\end{tabular}

Note: All data are expressed in wt.\%. Parentheses indicate standard deviations.

a (o) means that the position of an analysis point is on a lamella. (b) means that the position of an analysis point is between lamellae.

dicate standard deviations. Lamellae were observed in Sample 597C-8-3, 130-133 cm and in samples from deeper in the hole; mean values for such samples are given in Table 2 for measurements (o) on lamellae and (b) between lamellae. Figure 1 shows the variation of each component as a function of depth; bars indicate standard deviations. The weight percentages of $\mathrm{MnO}, \mathrm{CaO}, \mathrm{SiO}_{2}$, and $\mathrm{K}_{2} \mathrm{O}$ are almost constant. Generally, the values of $\mathrm{Al}_{2} \mathrm{O}_{3}$ and $\mathrm{MgO}$ decrease with depth in the hole. The ratio of $\mathrm{Fe}$ to Ti was calculated and is shown in Table 3 as $\mathrm{Fe} /(\mathrm{Fe}$ $+\mathrm{Ti})$.

Titanomagnetites are often found to be the carriers of remanent magnetization in most natural rocks. The composition parameter $x$ is used to indicate the proportion of ulvospinel in the titanomagnetite solid solution series, and is defined by

$$
x \mathrm{Fe}_{2} \mathrm{TiO}_{4} \cdot(1-x) \mathrm{Fe}_{3} \mathrm{O}_{4} \quad(0 \leq x \leq 1) .
$$

$x=0.0$ indicates magnetite and $x=1.0$ indicates ulvospinel. Submarine basalts are often reported to contain about $60 \%$ ulvospinel, whereas continental basalts are reported to contain nearly none (Marshall, 1978; Kono, 1980).

The $x$ values can be obtained in the $\mathrm{FeO}-\mathrm{Fe}_{2} \mathrm{O}_{3}-\mathrm{TiO}_{2}$ system, ignoring other components. $\mathrm{Fe} /(\mathrm{Fe}+\mathrm{Ti})$ and $x$ are represented as a function of depth in Figure 2. This figure shows that the titanomagnetite composition $(x)$ for samples from Hole $597 \mathrm{C}$ is generally 0.6 to 0.7 ; the mean value of $x$ is $0.68 \pm 0.12$. This value is similar to that reported for previous DSDP samples.

\section{THERMOMAGNETIC ANALYSIS AND ESTIMATION OF THE OXIDATION PARAMETER}

Thermomagnetic curves were obtained for 24 samples in a magnetic field of $4 \mathrm{kOe}$. A 200 - to $400-\mathrm{mg}$ sample was heated in the balance, which was constantly evacuated (below $1 \times 10^{-5} \mathrm{Torr}$ ), at temperatures up to $650^{\circ} \mathrm{C}$. Some thermomagnetic curves are shown in Figures 3, 4, and 5 .

It is inferred that, as indicated by the existence of lamellae, samples from deeper than $100 \mathrm{~m}$ had been affected by high-temperature oxidation. For example, the thermomagnetic curves for Samples 597C-9-3, 88-91 cm $(113.39 \mathrm{~m})$ and $597 \mathrm{C}-9-4,103-106 \mathrm{~cm}(115.05 \mathrm{~m})$ (Fig. 3) show high Curie temperatures in the heating process, and the heating and cooling curves are almost the same, indicating the effect of high-temperature oxidation. All samples from below $100 \mathrm{~m}$ show similar evidence of hightemperature oxidation.

Heating curves for Samples 597C-3-1, 131-134 cm $(56.83 \mathrm{~m})$ and $597 \mathrm{C}-4-1,60-63 \mathrm{~cm}(65.12 \mathrm{~m})$ (Fig. 4) are cone-shaped at temperatures above $400^{\circ} \mathrm{C}$, and the cooling curves, whose Curie temperatures are above $500^{\circ} \mathrm{C}$, steepen sharply. These curves are typical of samples affected by low-temperature oxidation. Judging from the thermomagnetic curves, other examples of low-temperature oxidation products are Hole 597C Samples 3-1, 131- 

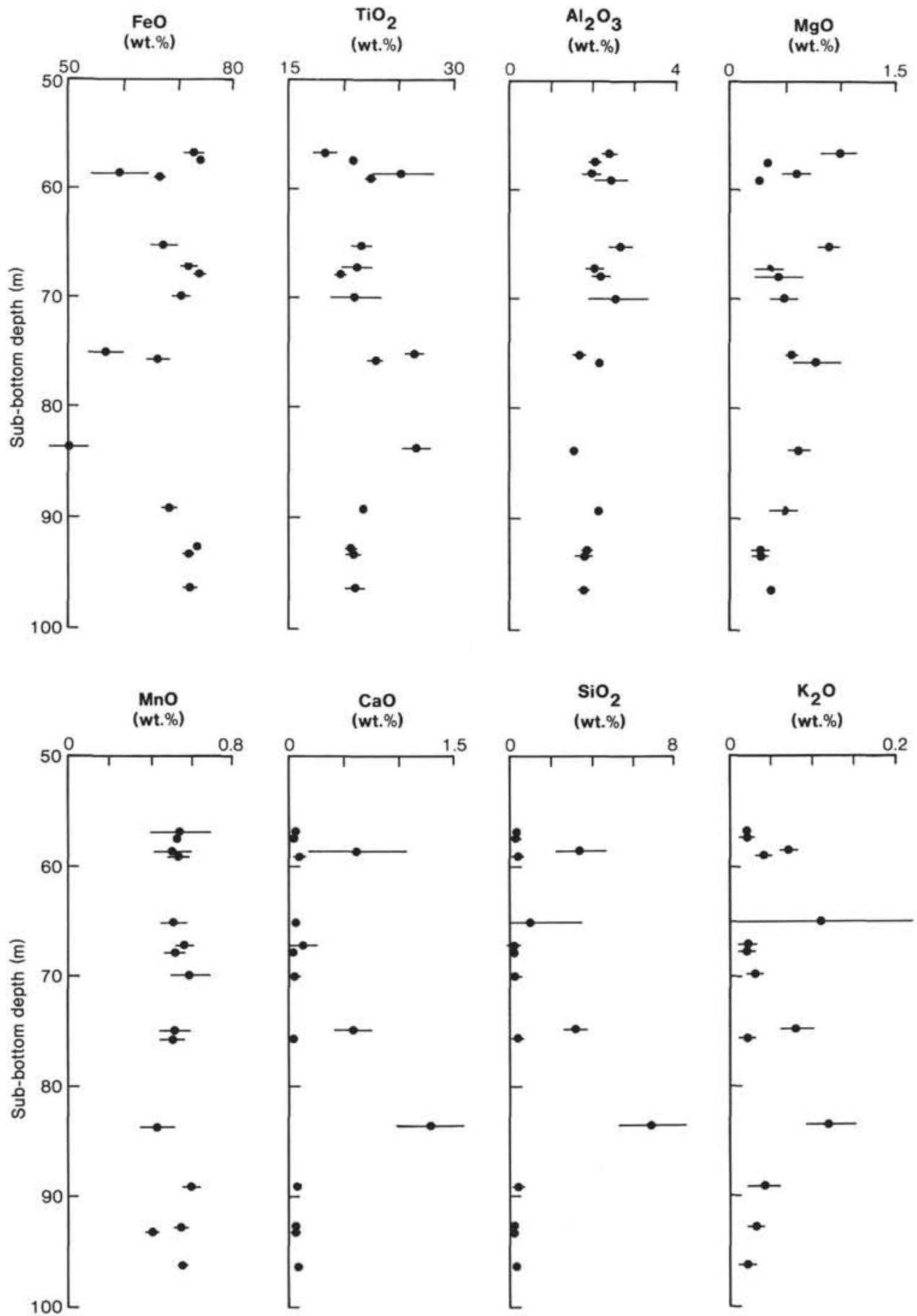

Figure 1. Variation of components $\mathrm{FeO}, \mathrm{TiO}_{2}, \mathrm{Al}_{2} \mathrm{O}_{3}, \mathrm{MgO}, \mathrm{MnO}, \mathrm{CaO}, \mathrm{SiO}_{2}$, and $\mathrm{K}_{2} \mathrm{O}$ as a function of depth. Bars indicate standard deviations.

$134 \mathrm{~cm} ; 3-3,5-8 \mathrm{~cm} ; 3-3,52-55 \mathrm{~cm} ; 4-1,60-63 \mathrm{~cm} ; 4-4$, $76-79 \mathrm{~cm} ; 5-1,129-132 \mathrm{~cm} ; 5-2,63-66 \mathrm{~cm} ; 6-1,109-$ $112 \mathrm{~cm} ; 6-5,58-61 \mathrm{~cm}$; and 7-4, 18-21 cm.

In contrast, Samples $597 \mathrm{C}-4-3,27-30 \mathrm{~cm}(67.79 \mathrm{~m})$ and $597 \mathrm{C}-7-1,115-118 \mathrm{~cm}(92.67 \mathrm{~m})$ showed little effect from low-temperature oxidation; the thermomagnetic curves are almost interchangeable, indicating low Curie temperatures of 160 to $210^{\circ} \mathrm{C}$ (Fig. 5).

For low-temperature oxidation, oxidation parameter $z$ can be estimated from the $T_{c}-z$ diagram of Nishitani and Kono (1983), using the $x$ values obtained by microprobe analyses and the Curie temperatures obtained from thermomagnetic curves. Nishitani (1981) showed, however, that the Curie temperature decreases as the amount of $\mathrm{Al}$ and/or $\mathrm{Mg}$ increases. Electron microprobe analyses show that the amount of $\mathrm{Al}_{2} \mathrm{O}_{3}$ in Hole $597 \mathrm{C}$ basalts is much greater than the amount of $\mathrm{MgO}$, so the effect of $\mathrm{MgO}$ is ignored here. The concentration of $\mathrm{Al}_{2} \mathrm{O}_{3}$ is about 2 wt. \%, which may decrease the Curie temperature by a maximum of $50^{\circ} \mathrm{C}$. Thus, the Curie tempera- 
Table 3. The ratio $\mathrm{Fe} /(\mathrm{Ti}+\mathrm{Ti}), x$, Curie temperature, and oxidation parameter $z$, Hole 597C samples.

\begin{tabular}{|c|c|c|c|c|c|c|c|c|c|}
\hline $\begin{array}{l}\text { Core-Section, } \\
\text { interval }(\mathrm{cm})\end{array}$ & $\mathrm{Fe} /(\mathrm{Fe}+\mathrm{Ti})$ & $x$ & $T_{1}$ & $T_{2}$ & $T_{3}$ & $z_{1}$ & $z_{2}$ & & $\begin{array}{c}\text { Sub-bottom } \\
\text { depth (m) }\end{array}$ \\
\hline $3-1,131-134$ & $0.817(0.010)$ & $0.550(0.030)$ & 468 & 578 & 545 & 0.90 & 0.33 & $(0.42)$ & 56.83 \\
\hline $3-2,40-43$ & $0.799(0.002)$ & $0.594(0.025)$ & 219 & & 152 & 0.18 & -0.04 & $(0.17)$ & 57.42 \\
\hline $3-3,5-8$ & $0.722(0.040)$ & $0.834(0.119)$ & 356 & 577 & 541 & - & 1.31 & $(0.36)$ & 58.57 \\
\hline $3-3,52-55$ & $0.768(0.006)$ & $0.697(0.017)$ & 364 & 589 & 538 & 0.77 & 1.03 & $(0.18)$ & 59.04 \\
\hline $4-1,60-63$ & $0.777(0.007)$ & $0.669(0.021)$ & 315 & 506 & 518 & 0.60 & 0.74 & $(0.23)$ & 65.12 \\
\hline $4-2,111-114$ & $0.790(0.014)$ & $0.629(0.043)$ & 226 & & 350 & 0.30 & 0.25 & $(0.19)$ & 67.13 \\
\hline $4-3,27-30$ & $0.807(0.005)$ & $0.579(0.016)$ & 201 & & 160 & 0.10 & 0.10 & $(0.21)$ & 67.79 \\
\hline $4-4,76-79$ & $0.788(0.022)$ & $0.635(0.067)$ & 340 & 518 & 492 & 0.62 & 0.45 & $(0.12)$ & 69.78 \\
\hline $5-1,129-132$ & $0.706(0.016)$ & $0.883(0.049)$ & 355 & 577 & 545 & - & 1.71 & $(0.41)$ & 74.81 \\
\hline $5-2,63-66$ & $0.764(0.009)$ & $0.708(0.027)$ & 366 & 592 & 546 & 0.78 & 0.93 & $(0.32)$ & 75.64 \\
\hline $6-1,109-112$ & $0.678(0.026)$ & $0.966(0.077)$ & 401 & 586 & 550 & - & 2.23 & $(0.31)$ & 83.61 \\
\hline $6-5,58-61$ & $0.777(0.006)$ & $0.670(0.017)$ & 316 & 563 & 532 & 0.61 & 0.70 & $(0.23)$ & 89.10 \\
\hline $7-1,115-118$ & $0.798(0.004)$ & $0.605(0.012)$ & 200 & & 165 & 0.13 & 0.002 & $(0.03)$ & 92.67 \\
\hline $7-2,16-18$ & $0.797(0.018)$ & $0.610(0.053)$ & 210 & & 163 & 0.18 & 0.31 & $(0.10)$ & 93.17 \\
\hline $7-4,18-21$ & $0.792(0.009)$ & $0.625(0.028)$ & 275 & 508 & 483 & 0.40 & 0.23 & $(0.10)$ & 96.20 \\
\hline $8-3,130-133$ & - & - & 500 & & 408 & - & 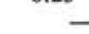 & & 104.82 \\
\hline $8-4,102-105$ & - & - & 484 & & 382 & - & - & & 106.04 \\
\hline $8-7,9-12$ & - & - & 449 & & 422 & - & - & & 109.61 \\
\hline $9-3,88-91$ & - & - & 556 & & 519 & - & - & & 113.39 \\
\hline $9-4,103-106$ & - & - & 506 & & 456 & - & - & & 115.05 \\
\hline $10-1,112-115$ & - & - & 504 & & 335 & - & - & & 119.64 \\
\hline $10-5,84-87$ & - & - & 492 & & 502 & - & - & & 125.36 \\
\hline $10-7,42-45$ & - & - & 497 & & 449 & - & - & & 127.93 \\
\hline $11-4,62-64$ & - & - & 508 & & 308 & - & - & & 132.63 \\
\hline
\end{tabular}

Note: $T_{l}=$ the first Curie temperatures observed during heating. $T_{2}=$ the highest Curie temperatures observed during heating. $T_{3}=$ Curie temperatures observed during cooling. $z_{1}=$ oxidation parameters determined using the $T_{C}-z$ diagram of Nishitani and Kono (1983). $z_{2}=$ oxidation parameters determined by electron microprobe analysis, assuming that the difference 100 minus the total percentage by weight is excess oxygen. Parentheses indicate standard deviations. Dashes indicate that values were not obtained; blanks in $T_{2}$ indicate that the second peak was not observed in a heating process.
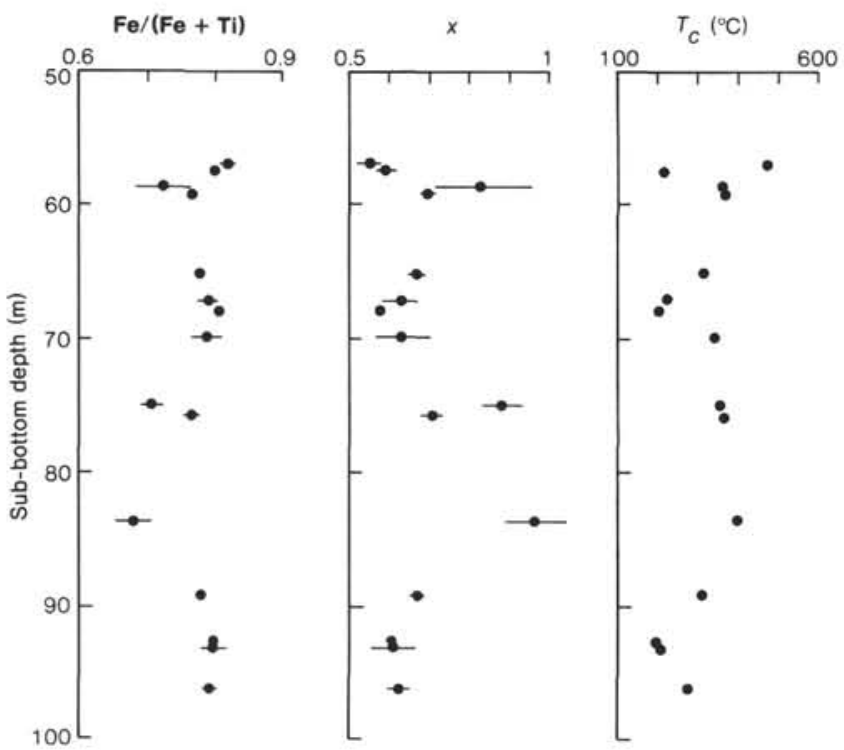

Figure 2. $\mathrm{Fe} /(\mathrm{Fe}+\mathrm{Ti}), x$ values, and Curie temperature $\left(T_{c}\right)$, as functions of depth. Bars indicate standard deviations.

tures determined from thermomagnetic curves may be offset by the presence of $\mathrm{Al}_{2} \mathrm{O}_{3}$, and the estimates of the titanomagnetite oxidation parameter $z$ may consequently be in error.

There is another way to calculate the oxidation parameter. This is to assume that the difference of $100 \mathrm{mi}-$ nus the total percentage by weight is excess oxygen. Values obtained by this method are shown in Table 3 as $z_{2}$.
This method leads to excessive error, however: Sample 597C-3-2, 40-43 cm indicates a negative oxidation state, and Samples 597C-3-3, 5-8 cm, 597C-3-3, 52-55 cm, 597C-5-1, 129-132 cm, and 597C-6-1, 109-112 cm indicate $z_{2}$ values greater than one. It is therefore assumed here that better estimates of the oxidation parameter can be obtained using Curie temperatures and the $\mathrm{Fe}$ to $\mathrm{Ti}$ ratios, although this method ignores the effects of impurities.

The amounts of the oxidation product so obtained are listed in Table 3 as $z_{1}$ and plotted on Figure 6. The $z$ values for samples affected by low-temperature oxidation vary widely, but they have a tendency to decrease as depth increases.

As already described, samples from deeper than $100 \mathrm{~m}$ had been affected by high-temperature oxidation, judging by microscopic observation of lamellae and by the characteristics of the thermomagnetic analysis. We can conclude that the magnetic properties of Hole 597C change at $100 \mathrm{~m}$ sub-bottom depth, and that low-temperature and high-temperature oxidation processes prevailed above $100 \mathrm{~m}$ and below $100 \mathrm{~m}$, respectively.

\section{REFERENCES}

Bence, A. E., and Albee, A. L., 1968. Emprical correction factors for the electron microanalysis of silicates and oxides. J. Geol., 76:382403.

Buddington, A. F., and Lindsley, D. H., 1964. Iron-titanium oxide minerals and synthetic equivalents. J. Petrol., 5:310-357.

Hamano, Y., Nishitani, T., and Kono, M., 1980. Magnetic properties of basalt samples from Deep Sea Drilling Project Holes 417D and 418A. In Donnelly, T., Francheteau, J., Bryan, W., Robinson, P., 
Flower, M., Salisbury, M., et al., Init. Repts. DSDP, 51, 52, 53, Pt. 2: Washington (U.S. Govt. Printing Office), 1391-1405.

Hauptman, Z., 1974. High temperature oxidation, range of non-stoichiometry and Curie point variation of cation deficient titanomagnetite $\mathrm{Fe}_{2.4} \mathrm{Ti}_{0.6} \mathrm{O}_{4}+\gamma$. Geophys. J. R. Astron. Soc., 38:29-47.

Kono, M., 1980. Magnetic properties of DSDP Leg 55 basalts. In Jackson, E. D., Koizumi, I., et al., Init. Repts. DSDP, 55: Washington (U.S. Govt. Printing Office), 723-736.

Marshall, M., 1978. The magnetic properties of some DSDP basalts from the North Pacific and inferences for Pacific Plate tectonics. $J$. Geophys. Res., 83:289-308.

Nishitani, T., 1981. Magnetic properties of titanomagnetites containing spinel $\left(\mathrm{MgAl}_{2} \mathrm{O}_{4}\right)$. J. Geomagn. Geoelectr., 33:171-179.
Nishitani, T., and Kono, M., 1983. Curie temperature and lattice constant of oxidized titanomagnetite. Geophys. J. R. Astron. Soc., 74:585-600.

Ozima, M., and Ozima, M., 1971. Characteristic thermomagnetic curve in submarine basalts. J. Geophys. Res., 76:2051-2056.

Ozima, M., and Sakamoto, N., 1971. Magnetic properties of synthesized titanomaghemite. J. Geophys. Res., 76:7035-7046.

Date of Initial Receipt: 16 July 1984 Date of Acceptance: 26 December 1984 

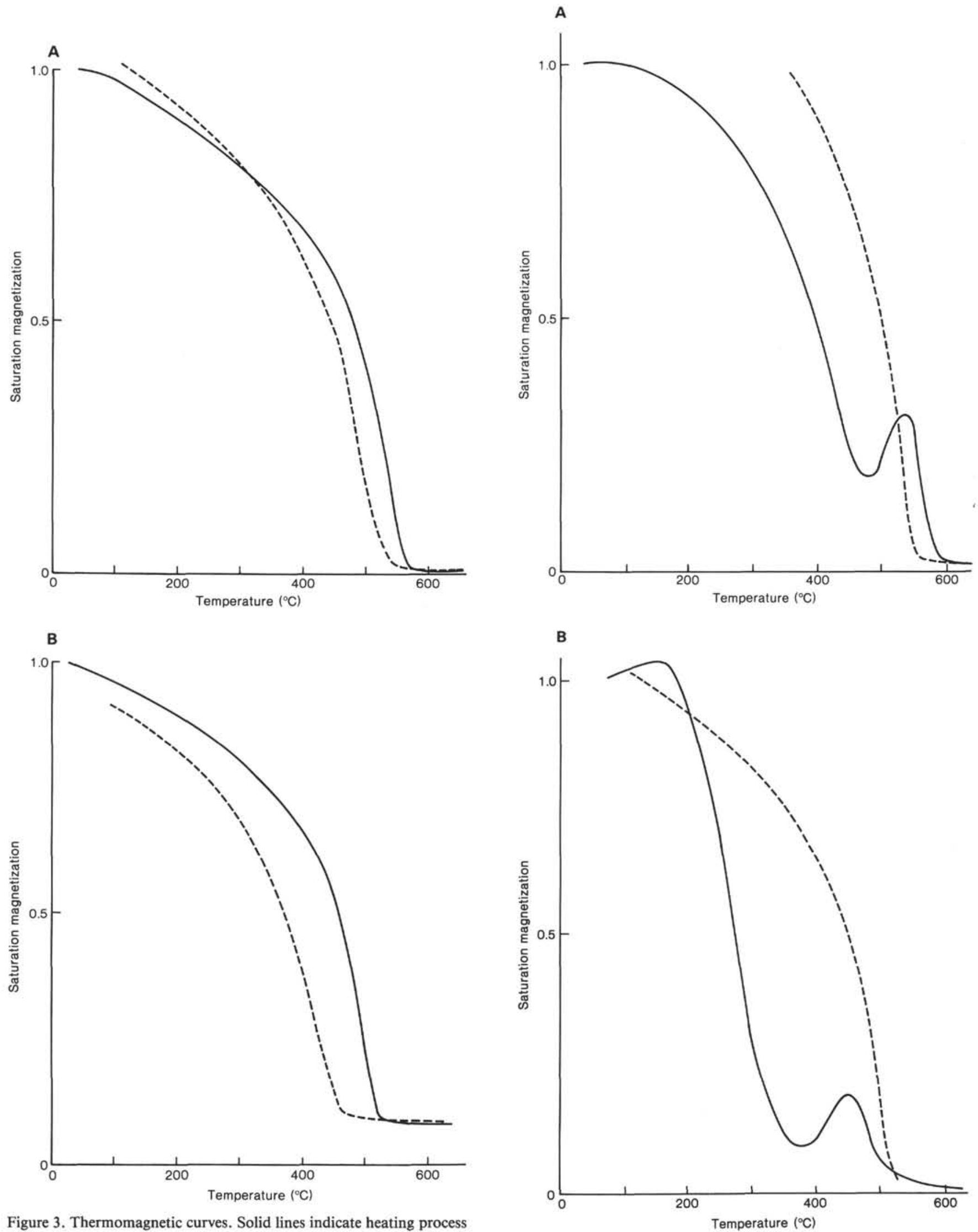

Figure 3. Thermomagnetic curves. Solid lines indicate heating process and dotted lines indicate cooling process. A. Sample 597C-9-3, 88$91 \mathrm{~cm}(113.39 \mathrm{~m})$. B. Sample 597C-9-4, 103-106 cm (115.05 m).

Figure 4. Thermomagnetic curves. Solid lines indicate heating process and dotted lines indicate cooling process. A. Sample 597C-3-1, 131$134 \mathrm{~cm}(56.83 \mathrm{~m})$. B. Sample 597C-4-1, 60-63 cm (65.12 m). 
A
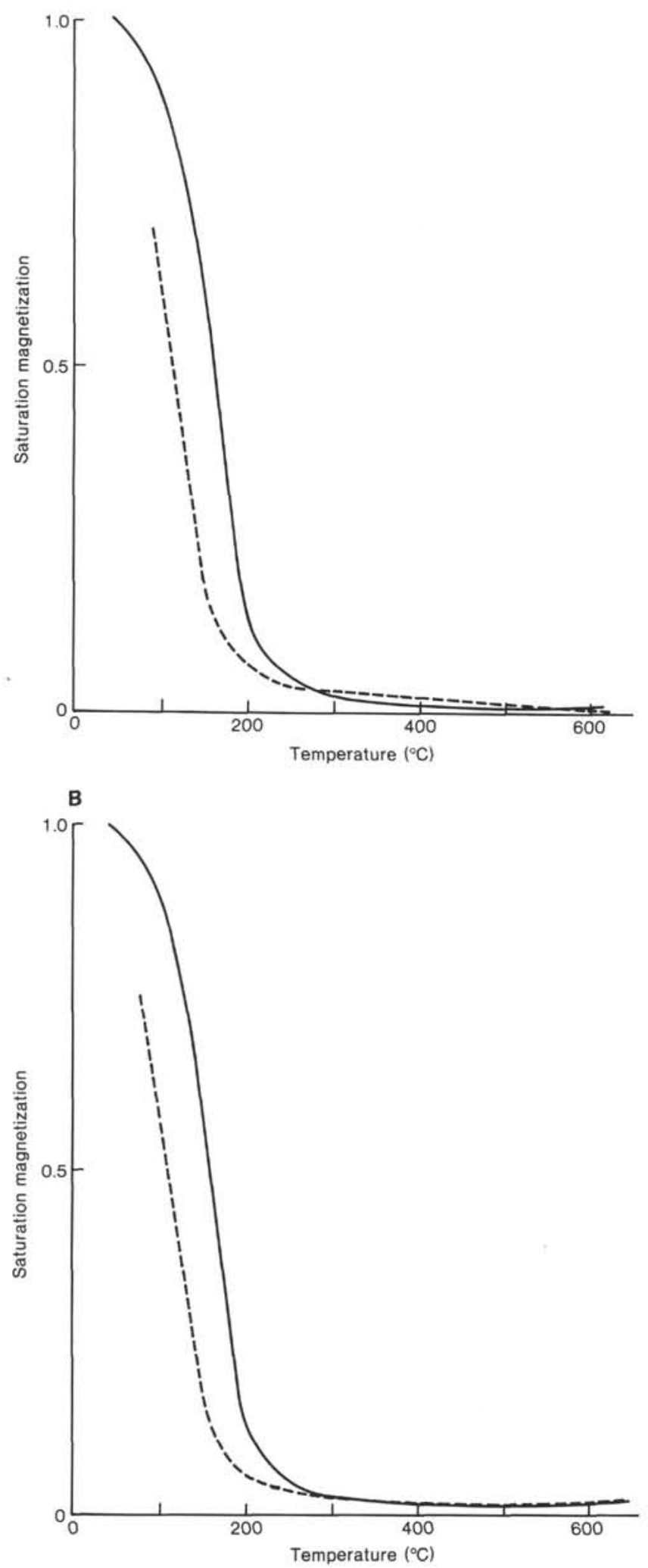

Figure 5. Thermomagnetic curves. Solid lines indicate heating process and dotted lines indicate cooling process. A. Sample 597C-4-3, 27$30 \mathrm{~cm}(67.79 \mathrm{~m})$. B. Sample 597C-7-1, 115-118 cm $(92.67 \mathrm{~m})$.

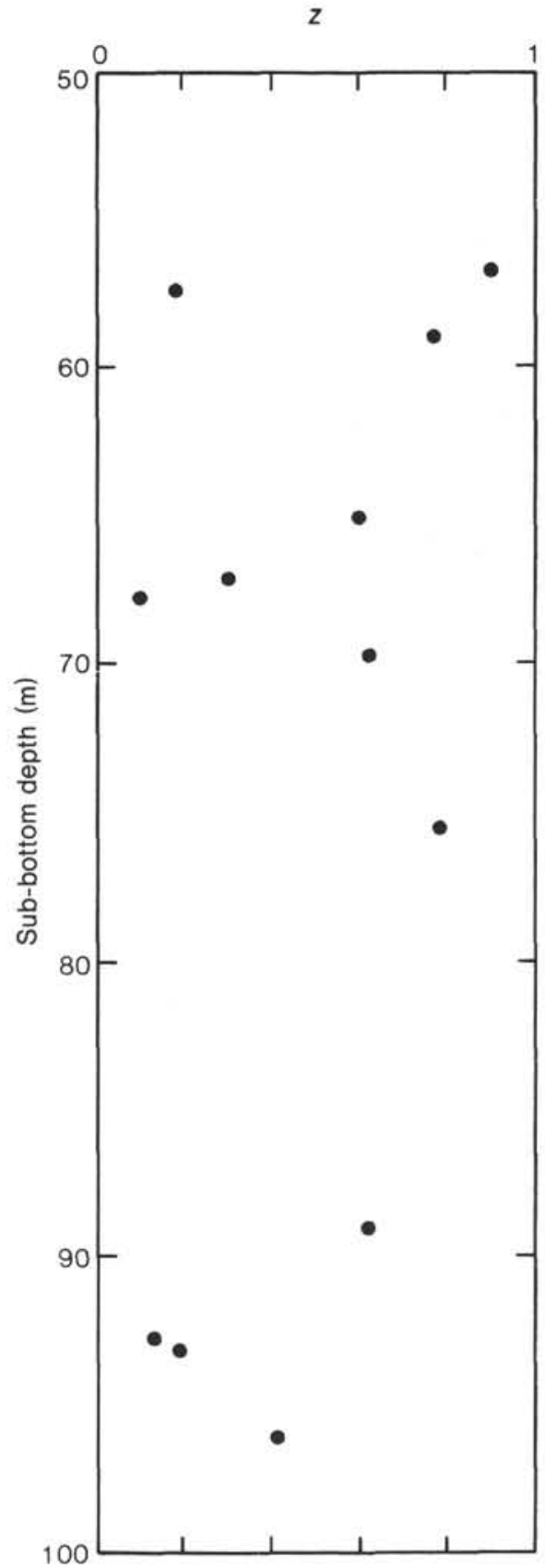

Figure 6. Oxidation parameter $(z)$ as a function of depth. 